PARtake: The Journal of Performance as Research Volume 4, Issue 1 - August 2021 ISSN: 2472-0860

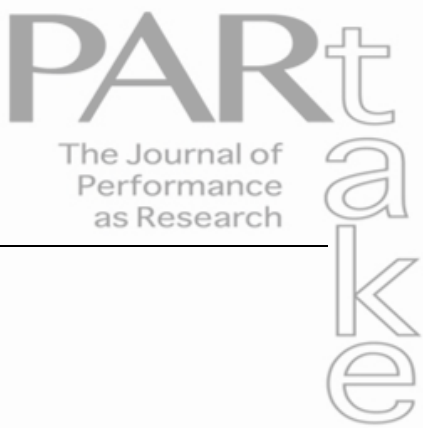

Kelley Holley - University of Maryland, College Park 


\section{Performance Review of Theatre For One: Here We Are}

Playwrights: DeLanna Studi, Nikkole Salter, Lynn Nottage, Lydia R. Diamond, Regina Taylor, Carmelita Tropicana, Stacey Rose, and Jaclyn Backhaus

Directors: Tamilla Woodard, Tiffany Nichole Greene, Taylor Reynolds, Rebecca Martinez, and Candis C. Jones

Produced by Theatre for One, Artistic Director Christine Jones

Commissioned by Arts Brookfield

Original Run: August 20- October 29, 2020

"Here we are, motherfuckas." Theatre for One: Here We Are begins by plunging its audience into silent darkness. Before the show, the audience was instructed to wear headphones and sit in a dark room. "Enter" commands the single illuminated button on an otherwise black screen. Once clicked, the spectator finds themself in a space less like a theatre lobby as we have come to expect it and more a chatroom circa 2000, complete with a blinking cursor and the promise of anonymity. The spectator is instructed to make their presence known by typing a message. As others, presumably audience members, follow suit, ephemeral messages float with no attached identifiers before slowly fading away, only to be replaced by new messages. Beyond the initial instruction, the time in this virtual lobby is unguided. The spectator messages with an unknown number of fellow audience members. Together as an audience, each spectator is singular and anonymous.

I saw Here We Are twice. In each performance, the audience utilized anonymity provided in the virtual lobby as an opportunity to express abstract thoughts, speak honesty, and build fleeting connections. Since there was no identification marker with a message, it was impossible to tell how many participants were present or who made what comment. In the chat, a spectator mused, "here we are, together." "Together" someone else echoed. Some posed questions: "Have you tried anything during quarantine you've never tried before?" An answer: "A zoom funeral." "That's sad. RIP.” Playing off the conceit of a virtual lobby, a spectator pretended to spot Bernadette Peters in the audience. A spectator reminded us of our bodies, asking if we could feel the back of our necks. "Always." "Can you hear your heart beating?" "Yes." This seemingly empty space was ultimately anything but. In an age of the internet in which so little anonymity remains, the virtual lobby harkened back to a bygone era in which the internet was new, a little dangerous, and always 
fresh. Seated before my computer, I was almost surprised that no one asked "A/S/L?" But no one did, preserving the freedom of expression found in anonymity. Without warning, stars filled the screen, one at a time. It was impossible to tell if the stars were sent from a single spectator, or if others joined in. Then, came a rain composed out of apostrophes. Rendering the digital as an embodied experience, someone said that they could feel the rain on their neck.

Sitting in the virtual lobby during my second viewing, I thought about how we were then presently many, all of us sitting anonymously in the dark, typing without self-censorship into a small text field to unknown interlocutors. Soon, we would be thrust into the light, in a video call with a live performer, who would see and hear us. Anonymous no more. I wrote, "From unseen to seen" and then quickly wrote "to scene." There were two types of responses: a conversational "Nice!" popped up, soon followed by "to obscene." And then "to see." Here we were together, riffing on each other's raindrops and observations. Repetition with revision, an audience who watched each other, infinite and unknowable, here and kindred.

The theatrical experience of Here We Are is split into two halves. The first is the extended time in the virtual lobby. The second half of the performance lives up to Theatre for One's name. After an indeterminate and varied stay in the lobby, the performance interface funnels the spectator into one of eight randomized microplays. Each spectator sees only one play, meaning that the vast majority of the microplays remain unseen, bar a repeat visit. Only luck determines which play the spectator sees and there is no guarantee one would not see the same play twice. For each performance of a microplay, there is a single spectator. The single actor speaks directly to them as if in conversation. The eight plays are all written by BIPOC female playwrights: DeLanna Studi, Nikkole Salter, Lynn Nottage, Lydia R. Diamond, Regina Taylor, Carmelita Tropicana, Stacey Rose and Jaclyn Backhaus. Each play grapples with the tumultuous present, a time that necessitates physical distance from each other, while also mandating that we be present and engaged in the political moment. As such, each microplay contends with being "here," now.

In the pandemic, it sometimes feels as if we are always "here." Here I am in my house, here I am in the now that lacks any temporal marking. "Here" stretches on, with almost a lack of "there" to point to. Being "here" asks us to be present. How difficult it is to be present, when it feels like there is only the present, with no change, to guide our experiences of each day. Instead, we can be here, present for one another. In Here We Are the spatial "here" is forgotten in favor of 
a shared presence that relies on togetherness. In its title, "we" is as integral as "here," reminding us of a shared presence as a core feature of theatre.

When I first attended Here We Are, I saw Thank You Letter by Jaclyn Backhaus, performed by Mahira Kakkar. In the performance, Kakkar writes a thank you letter to Representative John Lewis, who had passed away only a couple months prior. In particular, she focuses on his work on immigration and its impact on her life. My experience with Thank You Letter was ultimately short. I only saw half the play due to technical difficulties. The video suddenly ended, and I was moved to a "end-of-play" screen that let me take a picture and add comments before leaving the interface.

In my second visit, as expected, though no less startling, I abruptly exited the lobby and was brought into the bright beam of a headlamp, worn by performer Russell G. Jones in Nikkole Salter's microplay that shares its name with the event in its entirety. "Here we are, motherfucka!" he proclaims. Jones says that he is a space explorer who has set out to find a new home for the human race. He declares that he wants a plaque that says humanity's first words on their new home. "Here we are, motherfucka!"

As Jones mused on the notion of home, I was reminded of a conversation that had just occurred in the lobby. A fellow spectator asked, "What does it mean to be home?" Others replied that it is where they feel safe, accepted, and loved. It's where they laugh, it's where they rest. Someone mentions they're thinking of moving. Someone said, "home is where the heart is...so they say." "Where is your heart?" "Thumping in my ears." "That made me laugh." For me, this serendipitous moment created a bridge between the two spaces of performance, the dark and the light.

The perceived connection between the lobby experience and the performance was perhaps less fortuitous than I experienced it to be. After all, I can only presume I was speaking to other spectators and not "plants." And even if they were other spectators in genuine, it is to be expected that the themes of the plays inform our "pre-" show conversation. In all likelihood, the experience of lobby was more directed than the participatory experience let on. But perhaps it ultimately does not matter if the lobby was curated. Beyond the careful meditation and timeliness of the microplays, Here We Are offers its greatest impact through the device of the lobby as a framing device. As such, the spectator experiences two types of connection: that of being anonymous and that of being seen. The former is an experience not soon forgotten, permitting the spectator to be 
active, collaborative and creative without inhibitions. The second type of connection is all the better for having been proceeded by it.

The notion of "here" was a reoccurring concern throughout the play. Jones repeatedly asks the spectator if they have his location, and eagerly awaits their response as "mission control." He laughs, he plays, he differentiates between "motherfucker" and "motherfucka." He holds space for the potential indigenous life on the new planet, wary of repeating the mistakes of colonizers. Rather than discovering this world, he promises instead to learn any native language. In return, he will share soul music. Sorrow lies at the heart of Salter's microplay; explicitly, grief caused by climate change that lost humanity the earth, and the colonizing and racist practices that lost humanity its soul. Despite this profound sense of loss, the possibility for something new for us together is never out of sight. There is still the potential to share our joy, to share our time, to share our world.

In the final moments of the play, Jones gasps in wonder, his hands sprang to his face. "Oh there she is." He turns the camera, "Can you see her?" Slowly, the Earth appears on the horizon, a portrait of all of us together. Here we are. 